\title{
The rs6265 Polymorphism of the BDNF Gene Is Related to Higher-Lethality Suicide Attempts in the Korean Population
}

\author{
Seung-Gul Kang ${ }^{1}$, Jong Hun Lee ${ }^{2}$, Kwanghun Lee ${ }^{3}$, Hee-Cheol Kim ${ }^{4}$, Wan Seok Seo ${ }^{5}$, and Seunghee Won ${ }^{6 凶}$ \\ ${ }^{1}$ Department of Psychiatry, Gil Medical Center, Gachon University College of Medicine, Incheon, Republic of Korea \\ ${ }^{2}$ Department of Psychiatry, College of Medicine, Daegu Catholic University, Daegu, Republic of Korea \\ ${ }^{3}$ Department of Psychiatry, College of Medicine, Dongguk University, Gyeongju, Republic of Korea \\ ${ }^{4}$ Department of Psychiatry, Keimyung University School of Medicine, Daegu, Republic of Korea \\ ${ }^{5}$ Department of Psychiatry, College of Medicine, Yeungnam University, Daegu, Republic of Korea \\ ${ }^{6}$ Department of Psychiatry, School of Medicine, Kyungpook National University, Daegu, Republic of Korea
}

Objective Since the risk of suicide cannot be predicted by clinical symptoms alone, and suicide is known to have a genetic component, the discovery of genetic markers that can predict the lethality of suicide attempts is a clinically important topic. There have been many studies aiming to determine whether the rs6265 polymorphism of the BDNF gene is associated with suicidality; however, the results have been mixed, and there have been few studies investigating the relationship between this polymorphism and suicide attempt lethality.

Methods We assessed suicide lethality in 258 individuals who had attempted suicide using the relative risk ratio (RRR) scale and by genotyping the rs6265 polymorphism of the BDNF gene.

Results The RRR score for suicide attempts was higher in subjects with Met/Val and Val/Val genotypes than in that with a Met/Met genotype ( $\mathrm{p}=0.015)$. The RRR score for suicide attempts was also higher in Val allele carriers (Met/Val+Val/Val) than in Met/Met homozygotes $(\mathrm{p}=0.006)$.

Conclusion This study demonstrates the possibility that the rs6265 polymorphism of the BDNF gene could be used as a genetic marker to predict the lethality of suicide attempts, but more replication studies are needed for the application of this result in clinical practice.

Psychiatry Investig 2020;17(5):417-423

Key Words Suicide attempt, Lethality, Brain derived neurotrophic factor, Gene, rs6265.

\section{INTRODUCTION}

Suicide is one of the most serious health and social problems and is a worldwide phenomenon. According to statistics from 2017, the suicide rate in South Korea was 24.3 per 100,000 individuals. ${ }^{1}$ Although South Korea is a country with a declining suicide rate, its rate is still one of the highest among the Organization for Economic Cooperation and Development countries. Since the most important prevention is the early detection of groups at high risk for suicide, many studies and efforts to find high-risk groups have been steadily carried out, and many ge-

Received: January 12, 2020 Revised: February 23, 2020

Accepted: February 24, 2020

$\triangle$ Correspondence: Seunghee Won, MD, PhD

Department of Psychiatry, School of Medicine, Kyungpook National University, 130 Dongdeok-ro, Jung-gu, Daegu 41944, Republic of Korea

Tel: +82-53-200-5747, Fax: +82-53-426-5361, E-mail: wonsh864@knu.ac.kr

(ac) This is an Open Access article distributed under the terms of the Creative Commons Attribution Non-Commercial License (https://creativecommons.org/licenses/bync/4.0) which permits unrestricted non-commercial use, distribution, and reproduction in any medium, provided the original work is properly cited. netic studies have been conducted to identify candidate genes for suicidal behavior. Many studies on genetic associations have suggested that several genes, such as those encoding serotonin receptors and transporters, tryptophan hydroxylase, and brainderived neurotrophic factors (BDNFs), are related to suicidal behavior; however, these findings have not been consistently replicated. ${ }^{2}$

BDNF is a neurotrophic factor involved in the development and maintenance of neural cells ${ }^{3}$ and is important for cell survival and apoptosis in neural cells. ${ }^{4}$ Substantial evidence has shown that the BDNF gene has a connection with the genetic etiology of psychiatric disorders and suicidal behavior. ${ }^{5}$ Postmortem studies have shown reduced BDNF expression in suicide victims, ${ }^{6}$ and major depressive disorder patients who attempted suicide have shown decreased plasma levels of BDNF? BDNF is encoded by the BDNF gene located on chromosome $11,{ }^{8}$ and most genetic association studies between this gene and suicidal behavior were performed for the rs6265 polymorphism, which is also known as the Val66Met or G196A poly- 
morphism. ${ }^{9}$ The results of the association between the rs6265 single nucleotide polymorphism (SNP) and suicidal behavior are not conclusive, since both negative associations and positive associations have been reported (Table 1). ${ }^{5,8-29}$ Recently, Gonzalez-Castro et al. ${ }^{9}$ conducted a meta-analysis to evaluate the association between the rs6265 polymorphism and suicidal be-

Table 1. Previous genetic studies investigating the association between rs6265 and suicide behavior

\begin{tabular}{|c|c|c|c|c|}
\hline First author, year & Nation or ethnicity & $\begin{array}{c}\text { Number of subjects } \\
\text { (Suicidal/Nonsuicidal) }\end{array}$ & Diagnosis & Results \\
\hline \multicolumn{5}{|l|}{ Asian } \\
\hline Hwang et al., 2006 $6^{14}$ & Taiwan & $107(22 / 85)$ & Depression & No association \\
\hline Iga et al., $2007^{15}$ & Japan & $154(23 / 131)$ & Depression & $\begin{array}{l}\text { Met allele was related to suicidal } \\
\text { behavior }\end{array}$ \\
\hline Huang and Lee, $2007^{13}$ & Taiwan & $132(16 / 116)$ & Schizophrenia & $\begin{array}{l}\text { Met/Met genotype was associated } \\
\text { with suicide history }\end{array}$ \\
\hline Kim et al., $2008^{16}$ & Korea & $169(43 / 126)$ & Bipolar disorder & $\begin{array}{l}\text { Higher risk of suicidal attempt in } \\
\text { subjects with Met/Met genotype }\end{array}$ \\
\hline Ratta-Apha et al., $2013^{21}$ & Japan & $674(300 / 374)^{\ddagger}$ & Not available & No association \\
\hline Wang et al., $2015^{27}$ & China & $730(365 / 365)$ & Not available & $\begin{array}{l}\text { No association overall. However, } \\
\text { Val/Val genotype is related to suicide } \\
\text { attempt in elderly individuals }\end{array}$ \\
\hline Xia et al., $2018^{28}$ & China & $825(123 / 702)$ & Schizophrenia & $\begin{array}{l}\text { Association between Val allele and } \\
\text { suicide attempt }\end{array}$ \\
\hline $\begin{array}{l}\text { Gonzalez-Castro et al., } \\
2017^{9}\end{array}$ & Asia meta-analysis & 6 studies & Various diagnoses & $\begin{array}{l}\text { Increased suicide attempts in } \\
\text { subjects with } \mathrm{Val} / \mathrm{Val} \text { genotype }\end{array}$ \\
\hline Kim and Kim, $2018^{17}$ & Korea & $157(25 / 132)$ & Schizophrenia & $\begin{array}{l}\text { Suicide attempt is higher in subjects } \\
\text { with Met allele }\end{array}$ \\
\hline Choi et al., $2018^{11}$ & Korea & $212(69 / 143)$ & Mood disorders & No association \\
\hline \multicolumn{5}{|l|}{ Non-Asian } \\
\hline Vincze et al., $2008^{26}$ & $\begin{array}{l}\text { Switzerland, } \\
\text { france }\end{array}$ & $127(30 / 97)^{\dagger}$ & Bipolar disorder & $\begin{array}{l}\text { Increased frequency of violent suicidal } \\
\text { attempt in subjects with Val allele }\end{array}$ \\
\hline Sarchiapone et al., $2008^{22}$ & Italy & $170(97 / 73)$ & Depression & $\begin{array}{l}\text { Increased risk of suicidal behavior } \\
\text { in Met carriers }\end{array}$ \\
\hline Zarrilli et al., $2009^{8}$ & Slovenia & $512(262 / 250)$ & Not available & No association \\
\hline Schenkel et al., $2010^{23}$ & Brazil & $120(81 / 39)^{*}$ & $\begin{array}{l}\text { Major depressive } \\
\text { disorder }\end{array}$ & $\begin{array}{l}\text { Met allele is related to high lethality } \\
\text { in suicide attempts }\end{array}$ \\
\hline Spalletta et al., $2010^{25}$ & Italy & $119(33 / 86)$ & Schizophrenia & No association \\
\hline Neves et al., $2011^{19}$ & Brazil & $160(74 / 86)$ & Bipolar I disorder & No association \\
\hline Pregelj et al., $2011^{20}$ & Slovenia & $560(359 / 201)^{\ddagger}$ & Not available & $\begin{array}{l}\text { Increased frequency of female suicide } \\
\text { victims who are Met carriers }\end{array}$ \\
\hline Chojnicka et al., $2012^{12}$ & Poland & $1,066(517 / 549)^{\ddagger}$ & $\begin{array}{l}\text { Depression, schizophrenia, } \\
\text { and other or unknown }\end{array}$ & No association \\
\hline Nedic et al., $2013^{18}$ & Croatia & $691(112 / 579)$ & Alcohol dependence & No association \\
\hline Sears et al., $2013^{5}$ & New zealand & 565 & Bipolar disorder & No association \\
\hline Zai et al., $2015^{29}$ & Canada & $187(55 / 132)$ & Schizophrenia & No association \\
\hline Antypa et al., $2016^{10}$ & Belgium & $238(97 / 141)$ & Mood disorders & No association \\
\hline Schosser et al., $2017^{24}$ & $\begin{array}{l}\text { Multicenter } \\
\text { in Europe }\end{array}$ & 250 & Major depressive disorder & No association \\
\hline $\begin{array}{l}\text { Gonzalez-Castro et al., } \\
2017^{9}\end{array}$ & $\begin{array}{l}\text { Caucasian } \\
\text { meta-analysis }\end{array}$ & 8 studies & Various diagnoses & $\begin{array}{l}\text { Increased suicide attempts in } \\
\text { subjects with Met/Met genotype }\end{array}$ \\
\hline
\end{tabular}

*high-lethality suicide attempters/low-lethality suicide attempters, ${ }^{\dagger}$ violent suicide attempters/non-violent suicide attempters, ${ }^{\ddagger}$ suicide victims/ control 
havior, and they found no evidence of an association between the rs6265 polymorphism and suicidal behavior. However, subgroup analysis has shown increased suicidal risk in the Met/Met genotype group in Caucasian populations and increased suicidal risk in the $\mathrm{Val} / \mathrm{Val}$ genotype group in Asian populations. ${ }^{9}$

Four genetic association studies between the rs6265 polymorphism and suicidality have been reported in Koreans. ${ }^{11,16,17,30}$ The association between rs6265 SNP and bipolar disorder was not significant in a study of Korean bipolar disorder patients, but the association between suicide attempt and this SNP was significant in this sample, indicating that participants with the Met/Met genotype showed a 4.9-fold higher risk of suicide attempt than those with the Val/Val genotype. ${ }^{16}$ In a study conducted in Korean schizophrenia patients, a higher frequency of suicide attempts in subjects with the Met allele was reported. ${ }^{17}$ However, Choi et al. ${ }^{11}$ reported no association between rs6265 and suicide attempts in patients with mood disorder. A study of older adults aged 65 years or older showed no association between suicidal ideation and the rs6265 polymorphism and deviation from Hardy-Weinberg equilibrium..$^{30}$ Thus, to date, no consistent conclusions can be drawn from association studies between the rs6265 SNP and suicidal behavior in Koreans.

There have been many genetic association studies between rs6265 and suicide, but few studies have compared the lethality of suicide attempts among rs6265 genotypes. A suicide attempt is a dangerous act with the intent to die, but there is a wide range of lethality among suicidal behaviors. Therefore, the relationship between the lethality of suicidal behavior and the rs6265 SNP is of clinical significance. This study was conducted to investigate the relationship between the rs6265 polymorphism and the lethality of suicide attempts in Koreans.

\section{METHODS}

\section{Subjects}

All participants $(n=258)$ were suicide attempters, and they were enrolled in this study from emergency rooms at 5 university hospitals in Daegu-Gyeongbuk province. A suicide attempt was defined as a self-directed harmful behavior with some intent to die. Trained psychiatric residents interviewed suicide attempters after patients had recovered from a medically acute state, just before discharge from the hospital. The psychiatric residents evaluated and diagnosed the patients using a structured questionnaire about suicide and psychiatric diagnoses with reference to the Diagnostic and Statistical Manual of Mental Disorders, 4th edition, text revision. ${ }^{31}$ A board-certified psychiatrist at each hospital confirmed the participants' psychiatric diagnoses based on a review of their medical records and case report form.
The Institutional Review Boards in the Kyungpook National University Hospital (approved number KNUH 2011-04-014003) and four other university hospitals approved this study. All the participants and caregivers received written and verbal explanations regarding the study and provided written informed consent.

\section{Genotyping}

Three cubic centimeters of venous blood was collected from each participant, and genomic DNA was isolated from peripheral blood leukocytes using the Qiagen QIAamp Blood Kit (Qiagen, Valencia, CA, USA). The DNA concentration was determined using a NanoDrop ND-1000 spectrophotometer (Thermo Fisher Scientific, Wilmington, DE), and the purity of the DNA was assessed based on a 260/280 $\mathrm{nm}$ absorbance ratio from 1.7 to 2.1 . The rs6265 polymorphism was genotyped using a previously described method, ${ }^{5,32}$ and all genotyping procedures were performed at D\&P Biotech, Inc. (Daegu, Korea). The genotyping was performed by melting-curve analysis using fluorescence-labeled hybridization probes (LightCycler 480 Instrument, Roche Diagnostic GmbH, Mannheim, Germany).

\section{Assessment of suicide attempt lethality and depression severity}

The lethality of individual suicidal behaviors was evaluated using Weisman and Worden's risk-rescue rating (RRR) system. ${ }^{33}$ According to the RRR system, lethality can be expressed as a ratio of five risk and five rescue factors, and the total risk and rescue point scores range from 1 to 5 , respectively. ${ }^{33}$ The RRR score is determined by the formula [risk score/(risk score+rescue score) $\times 100 .^{33}$ The severity of depression was evaluated by a psychiatrist using the validated Korean version of the Hamilton Depression Rating Scale (K-HDRS) ${ }^{34}$ Impulsivity was evaluated using the validated Korean version of the Barratt Impulsiveness Scale II (BIS II). ${ }^{35}$

\section{Statistical analysis}

Conformity with the Hardy-Weinberg equilibrium (HWE) was tested using the $\chi^{2}$ test for goodness of fit. We used chisquared tests or Fisher's exact test and analysis of variance to analyze categorical and normally distributed continuous variables, respectively. To analyze nonnormally distributed continuous variables, Kruskal-Wallis or Mann-Whitney tests were used. The cutoff for statistical significance was set at $\mathrm{p}<0.05$. Statistical Package for the Social Sciences for Windows ver. 23.0 (IBM Corp., Armonk, NY, USA) was used to analyze the data. 


\section{RESULTS}

\section{Demographic and clinical characteristics of participants and their comparison among the three genotypes}

The participants' demographic data, severity of depression, BIS total scores, clinical information (methods of suicide attempt, alcohol use at the time of a suicide attempt, current psychiatric treatment, and presence of medical illnesses which interfered with daily life), and principal psychiatric diagnosis as well as comparisons across the three genotypes are presented in Table 2 . The participants were $43.3 \pm 17.7$ years old (mean \pm SD), and they comprised 109 (42.2\%) males and 149 (57.8\%) females (Table 2). The mean ages and sex ratio of the subjects, the proportion of psychiatric diagnoses, and the K-HDRS and BIS total scores did not differ among the three genotype groups (Table 2). The comparison of several clinical variables (methods of suicide attempt, alcohol use at the time of a suicide attempt, presence of psychiatric treatment, and presence of medical illness) did not reveal statistically significant differences among the three genotype groups (Table 2). The genotype frequency in the participants did not deviate from the HWE for rs6265 $\left(\chi^{2}=0.167, \mathrm{p}=0.682\right)$.

\section{Comparison of lethality of suicide attempts among the genotypes}

A comparison of RRR score and the number of previous suicide attempts among the three genotype groups of rs6265 is presented in Table 3. The RRR score for suicide attempts was higher in subjects with Met/Val and Val/Val genotypes than in those with a Met/Met genotype $\left(\chi^{2}=8.36, p=0.015\right)$ (Table 3). The RRR score for suicide attempts was also higher in participants who were Val allele carriers (Met/Val+Val/Val) than in Met/Met homozygotes ( $\mathrm{Z}=-2.75, \mathrm{p}=0.006$ ) (Table 4). The number of previous suicide attempts did not differ among the three genotypes of rs6265 (Table 3).

Table 2. Demographic and clinical variables of patients in the three rs6265 genotype groups

\begin{tabular}{|c|c|c|c|c|c|c|}
\hline \multirow[b]{2}{*}{ Age (years old) } & \multirow{2}{*}{$\begin{array}{c}\begin{array}{c}\text { Total } \\
(\mathrm{N}=258)\end{array} \\
43.3 \pm 17.7\end{array}$} & \multirow{2}{*}{$\begin{array}{c}\text { Met/Met } \\
(\mathrm{N}=57) \\
42.1 \pm 17.3\end{array}$} & \multirow{2}{*}{$\begin{array}{l}\text { Met/Val } \\
(\mathrm{N}=132) \\
42.4 \pm 18.1\end{array}$} & \multirow{2}{*}{$\begin{array}{l}\mathrm{Val} / \mathrm{Val} \\
(\mathrm{N}=69) \\
45.9 \pm 17.2\end{array}$} & \multicolumn{2}{|c|}{ Statistics* } \\
\hline & & & & & $\mathrm{F}=1.06$ & $\mathrm{p}=0.347$ \\
\hline $\operatorname{Sex}(m / f)$ & $109 / 149$ & $22 / 35$ & $56 / 76$ & $31 / 38$ & $\chi^{2}=0.52$ & $\mathrm{p}=0.773$ \\
\hline Education (years) & $11.0 \pm 3.9$ & $10.8 \pm 4.0$ & $11.1 \pm 3.9$ & $11.0 \pm 3.9$ & $\mathrm{~F}=0.10$ & $\mathrm{p}=0.903$ \\
\hline K-HDRS & $15.4 \pm 7.2$ & $15.6 \pm 6.8$ & $15.4 \pm 7.6$ & $15.2 \pm 6.8$ & $\mathrm{~F}=0.05$ & $\mathrm{p}=0.950$ \\
\hline BIS-Total & $56.4 \pm 9.7$ & $55.4 \pm 8.9$ & $56.1 \pm 10.2$ & $57.6 \pm 9.3$ & $\mathrm{~F}=0.77$ & $\mathrm{p}=0.463$ \\
\hline \multicolumn{7}{|l|}{ Methods of suicide attempt (\%) } \\
\hline Ingestion of medications & $125(48.4)$ & $31(54.4)$ & $61(46.2)$ & $33(47.8)$ & $\chi^{2}=10.25$ & $\mathrm{p}=0.567$ \\
\hline Ingestion of pesticides or chemicals & $79(30.6)$ & $15(26.3)$ & $42(31.8)$ & $22(31.9)$ & & \\
\hline Hanging & $12(4.7)$ & $5(8.8)$ & $4(3.0)$ & $3(4.3)$ & & \\
\hline Jumping & $4(1.6)$ & $0(0)$ & $3(2.3)$ & $1(1.4)$ & & \\
\hline Inhalation & $17(6.6)$ & $1(1.8)$ & $13(9.8)$ & $3(4.3)$ & & \\
\hline Cutting & $16(6.2)$ & $4(7.0)$ & $7(5.3)$ & $5(7.2)$ & & \\
\hline Others & $5(1.9)$ & $1(1.8)$ & $2(1.5)$ & $2(2.9)$ & & \\
\hline \multicolumn{7}{|l|}{ Psychiatric diagnosis } \\
\hline Depressive disorder & 169 & $34(59.6)$ & $86(65.2)$ & $49(71)$ & $\chi^{2}=8.57$ & $\mathrm{p}=0.572$ \\
\hline Bipolar disorder & 26 & $8(14)$ & $14(10.6)$ & $4(5.8)$ & & \\
\hline Psychotic disorder & 21 & $3(5.3)$ & $13(9.8)$ & $5(7.2)$ & & \\
\hline Anxiety disorder & 1 & $0(0)$ & $1(0.8)$ & $0(0)$ & & \\
\hline Adjustment disorder & 31 & $9(15.8)$ & $12(9.1)$ & $10(14.5)$ & & \\
\hline Other & 10 & $3(5.3)$ & $6(4.5)$ & $1(1.4)$ & & \\
\hline Alcohol use at the time of suicide attempt (\%) & $114(44.4)$ & $25(43.9)$ & $56(42.7)$ & $33(47.8)$ & $\chi^{2}=0.48$ & $\mathrm{p}=0.787$ \\
\hline Under psychiatric treatment (\%) & $74(28.8)$ & $21(36.8)$ & $36(27.3)$ & $17(25.0)$ & $\chi^{2}=2.43$ & $\mathrm{p}=0.297$ \\
\hline Use of psychotropic medication (\%) & $96(37.2)$ & $23(40.4)$ & $52(39.4)$ & $21(30.4)$ & $\chi^{2}=1.87$ & $\mathrm{p}=0.393$ \\
\hline Presence of medical illness (\%) & $47(18.3)$ & $10(17.5)$ & $21(15.9)$ & $16(23.5)$ & $\chi^{2}=1.77$ & $\mathrm{p}=0.412$ \\
\hline
\end{tabular}

The values are the means \pm SD or number of participants (percentage). *analysis of variance, chi-squared test, or Fisher's exact test. K-HDRS: Korean version of the Hamilton Depression Rating Scale, BIS: Barratt Impulsiveness Scale 
Table 3. Comparison of the relative risk ratio scores of current suicidal attempt and the number of previous suicidal attempts among the three rs6265 genotype groups

\begin{tabular}{lcccc}
\hline & Met/Met $(\mathrm{N}=57)$ & Met/Val $(\mathrm{N}=132)$ & $\mathrm{Val} / \mathrm{Val}(\mathrm{N}=69)$ & \multicolumn{2}{c}{ Statistics* } \\
\hline Previous suicidal attempts & $2.0 \pm 1.2$ & $1.9 \pm 1.6$ & $1.8 \pm 1.6$ & $\mathrm{~F}=0.15$ \\
Relative risk ratio & $27.9 \pm 12.0$ & $33.9 \pm 13.4$ & $32.1 \pm 13.3$ & $\mathrm{p}=0.858$ \\
\hline
\end{tabular}

The values are the means \pm SD. *analysis of variance or Kruskal-Wallis test, ${ }^{\dagger}$ significance at $\mathrm{p}<0.05$

Table 4. Comparison of the relative risk ratio score of suicide attempt between rs6265 Val carriers and Met/Met homozygotes

\begin{tabular}{cccc}
\hline & Met/Val+Val/Val $(\mathrm{N}=201)$ & Met $/$ Met $(\mathrm{N}=57)$ & Statistics* $^{*}$ \\
\hline Relative risk ratio & $33.3 \pm 13.4$ & $27.9 \pm 12.0$ & $\mathrm{Z}=-2.75, \mathrm{p}=0.006^{\dagger}$ \\
\hline
\end{tabular}

The values are the means \pm SD. ${ }^{*}$ Mann-Whitney test, ${ }^{\dagger}$ significance at $\mathrm{p}<0.05$

\section{DISCUSSION}

The present study investigated the difference in the RRR of current suicide attempts among the rs6265 polymorphism genotypes of the BDNF gene. We identified more lethal suicide attempts in Val carriers (Val/Val+Met/Val) than Met/Met homozygotes of the rs6265 SNP. To the best of our knowledge, this is the first report to investigate the relationship between lethality of suicide and the rs6265 SNP in Asian and Korean populations.

The results from similar research topics have been reported in bipolar disorder patients in Switzerland and France ${ }^{26}$ and in major depressive disorder patients in Brazil. ${ }^{23}$ Violent (or lethal) suicide attempts (e.g., hanging, use of firearms or knives, and jumping from heights) were associated with the Val allele of the rs6265 SNP in the Swiss and French populations $^{26}$ and with the Met allele in the Brazilian population (Caucasian $75 \%)^{23}$

There was no report of the relationship between the lethality of suicide and the rs6265 SNP in Asian or Korean populations prior to this study. Several studies in Asian populations have reported a higher risk of suicide attempt in subjects with the Met allele or a Met/Met genotype, ${ }^{13,15-17}$ although others have reported a significant association between the $\mathrm{Val} / \mathrm{Val}$ genotype and risk of suicide ${ }^{27,28}$ or no association. ${ }^{11,14,21}$ Recently, Gonzalez-Castro et al. ${ }^{9}$ reported increased suicidal risk in the Val/Val genotype group in Asian populations by metaanalysis using data from six previous studies, and this result is partially in line with our research. The discrepancy between the results of the meta-analysis (higher risk in those with the $\mathrm{Val} /$ Val genotype) and the results in the majority of previous reports (higher risk in those with the Met allele or Met/Met genotype) might be explained by the fact that the primary goal of most previous studies is to study the association between psychiatric disorder with the rs6265 SNP and the number of suicide attempters is generally small. ${ }^{9}$ Studies on this topic performed in Korea do not show consistent results either, ${ }^{11,16,17,30}$ so further studies are needed.
A previous study reported different allele frequencies between Asian and European populations. ${ }^{21}$ These large interracial differences in the genotype frequency of the rs6265 polymorphism may have resulted in inconsistent results in previous studies due to genetic-ethnic dependency. ${ }^{9,36}$ According to racespecific data on allele frequency, the rs6265 allele frequency in the Korean population showed a relatively higher frequency of the Met allele than other races, ${ }^{37}$ and the allele frequency (Met:Val=0.48:0.52) in our study was similar to the frequency in these data.

A limitation of this study was that there was no control group for suicide attempters, so we could not show a genetic association between rs6265 and suicide attempt. Because the study population was based on suicide attempters who visited the emergency room, it was difficult to establish a suitable control group. However, because interviews in this study were conducted in the emergency room after suicide attempt, our study has strength in that the information on the lethality, method, and motivation of the suicide attempt is relatively accurate compared to that in studies based on long-term recall. In addition, because suicidality was defined as an emergency room admission after an actual suicide attempt rather than suicidal ideation, we think that this research was performed using a clearer and more appropriate phenotype. Another limitation is that the Korean version of the RRR scale, a tool for evaluating the lethality of suicide attempts, has not been validated. However, since this scale consists of short words or phrases and is evaluated by the clinician, we did not believe that the scale was linguistically problematic. Indeed, a number of studies have used this scale in Korea. ${ }^{38-40}$

We hope that the relationship between the rs6265 polymorphism and the lethality of suicide attempts described in this study will be useful for predicting serious suicide risk in future clinical practice. However, to apply the results of this study to clinical practice, replication studies on more subjects, including healthy controls, are needed. 


\section{Acknowledgments}

This work was supported by the Biomedical Research Institute Grant from Kyungpook National University Hospital (2011). This research was also supported by a grant of the Korea Health Technology R\&D Project through the Korea Health Industry Development Institute (KHIDI), funded by the Ministry of Health \& Welfare, Republic of Korea (grant number: HI17C2665).

\section{Conflicts of Interest}

The authors have no potential conflicts of interest to disclose.

\section{Author Contributions}

Conceptualization: Seunghee Won. Data curation: Jong Hun Lee, Kwanghun Lee, Hee-Cheol Kim, Wan Seok Seo, Seunghee Won. Formal analysis: SeungGul Kang. Funding acquisition: Seunghee Won, Seung-Gul Kang. Investigation: Jong Hun Lee, Kwanghun Lee, Hee-Cheol Kim, Wan Seok Seo, Seunghee Won. Methodology: Seunghee Won. Project administration: Seunghee Won. Resources: Seunghee Won. Software: Seunghee Won. Supervision: Seunghee Won. Validation: Seunghee Won, Seung-Gul Kang. Visualization: Seunghee Won, Seung-Gul Kang. Writing_-original draft: Seung-Gul Kang, Seunghee Won. Writing_-review \& editing: Seunghee Won.

\section{ORCID iDs}

$\begin{array}{ll}\text { Seung-Gul Kang } & \text { https://orcid.org/0000-0003-4933-0433 } \\ \text { Jong Hun Lee } & \text { https://orcid.org/0000-0002-3581-5029 } \\ \text { Kwanghun Lee } & \text { https://orcid.org/0000-0003-4531-8015 } \\ \text { Hee-Cheol Kim } & \text { https://orcid.org/0000-0001-7957-4872 } \\ \text { Wan Seok Seo } & \text { https://orcid.org/0000-0002-5122-5360 } \\ \text { Seunghee Won } & \text { https://orcid.org/0000-0002-4858-6173 }\end{array}$

\section{REFERENCES}

1. Statistics Korea. Annual Report of the Cause of Death Statistics. Daejeon: Statistics Korea; 2017.

2. Mirkovic B, Laurent C, Podlipski MA, Frebourg T, Cohen D, Gerardin P. Genetic association studies of suicidal behavior: a review of the past 10 years, progress, limitations, and future directions. Front Psychiatry 2016;7:158.

3. Maisonpierre PC, Le Beau MM, Espinosa R 3rd, Ip NY, Belluscio L, de la Monte SM, et al. Human and rat brain-derived neurotrophic factor and neurotrophin-3: gene structures, distributions, and chromosomal localizations. Genomics 1991;10:558-568.

4. Webster MJ, Weickert CS, Herman MM, Kleinman JE. BDNF mRNA expression during postnatal development, maturation and aging of the human prefrontal cortex. Brain Res Dev Brain Res 2002;139:139-150.

5. Sears C, Wilson J, Fitches A. Investigating the role of BDNF and CCK system genes in suicidality in a familial bipolar cohort. J Affect Disord 2013;151:611-617.

6. Karege F, Vaudan G, Schwald M, Perroud N, La Harpe R. Neurotrophin levels in postmortem brains of suicide victims and the effects of antemortem diagnosis and psychotropic drugs. Brain Res Mol Brain Res 2005;136:29-37.

7. Kim YK, Lee HP, Won SD, Park EY, Lee HY, Lee BH, et al. Low plasma BDNF is associated with suicidal behavior in major depression. Prog Neuropsychopharmacol Biol Psychiatry 2007;31:78-85.

8. Zarrilli F, Angiolillo A, Castaldo G, Chiariotti L, Keller S, Sacchetti S, et al. Brain derived neurotrophic factor (BDNF) genetic polymorphism (Val66Met) in suicide: a study of 512 cases. Am J Med Genet B Neuropsychiatr Genet 2009;150b:599-600.

9. Gonzalez-Castro TB, Salas-Magana M, Juarez-Rojop IE, Lopez-Narvaez ML, Tovilla-Zarate CA, Hernandez-Diaz Y. Exploring the association between BDNF Val66Met polymorphism and suicidal behavior: meta-analysis and systematic review. J Psychiatr Res 2017;94:208-217.

10. Antypa N, Souery D, Tomasini M, Albani D, Fusco F, Mendlewicz J, et al. Clinical and genetic factors associated with suicide in mood disor- der patients. Eur Arch Psychiatry Clin Neurosci 2016;266:181-193.

11. Choi HY, Kim GE, Kong KA, Lee YJ, Lim WJ, Park SH, et al. Psychological and genetic risk factors associated with suicidal behavior in Korean patients with mood disorders. J Affect Disord 2018;235:489-498.

12. Chojnicka I, Strawa K, Fudalej S, Fudalej M, Pawlak A, Kostrzewa G, et al. Analysis of four genes involved in the neurodevelopment shows association of rs4307059 polymorphism in the cadherin 9/10 region with completed suicide. Neuropsychobiology 2012;66:134-140.

13. Huang TL, Lee CT. Associations between brain-derived neurotrophic factor G196A gene polymorphism and clinical phenotypes in schizophrenia patients. Chang Gung Med J 2007;30:408-413.

14. Hwang JP, Tsai SJ, Hong CJ, Yang CH, Lirng JF, Yang YM. The Val$66 \mathrm{Met}$ polymorphism of the brain-derived neurotrophic-factor gene is associated with geriatric depression. Neurobiol Aging 2006;27:18341837.

15. Iga J, Ueno S, Yamauchi K, Numata S, Tayoshi-Shibuya S, Kinouchi S, et al. The Val66Met polymorphism of the brain-derived neurotrophic factor gene is associated with psychotic feature and suicidal behavior in Japanese major depressive patients. Am J Med Genet B Neuropsychiatr Genet 2007;144b:1003-1006.

16. Kim B, Kim CY, Hong JP, Kim SY, Lee C, Joo YH. Brain-derived neurotrophic factor Val/Met polymorphism and bipolar disorder. Association of the Met allele with suicidal behavior of bipolar patients. Neuropsychobiology 2008;58:97-103.

17. Kim EJ, Kim YK. 196G/A of the brain-derived neurotrophic factor gene polymorphisms predicts suicidal behavior in schizophrenia patients. Psychiatry Investig 2018;15:733-738.

18. Nedic G, Perkovic MN, Sviglin KN, Muck-Seler D, Borovecki F, Pivac N. Brain-derived neurotrophic factor Val66Met polymorphism and alcohol-related phenotypes. Prog Neuropsychopharmacol Biol Psychiatry 2013;40:193-198.

19. Neves FS, Malloy-Diniz L, Romano-Silva MA, Campos SB, Miranda $\mathrm{DM}$, De Marco L, et al. The role of BDNF genetic polymorphisms in bipolar disorder with psychiatric comorbidities. J Affect Disord 2011;131: 307-311.

20. Pregelj P, Nedic G, Paska AV, Zupanc T, Nikolac M, Balazic J, et al. The association between brain-derived neurotrophic factor polymorphism (BDNF Val66Met) and suicide. J Affect Disord 2011;128:287-290.

21. Ratta-Apha W, Hishimoto A, Yoshida M, Ueno Y, Asano M, Shirakawa $\mathrm{O}$, et al. Association study of BDNF with completed suicide in the Japanese population. Psychiatry Res 2013;209:734-736.

22. Sarchiapone M, Carli V, Roy A, Iacoviello L, Cuomo C, Latella MC, et al. Association of polymorphism (Val66Met) of brain-derived neurotrophic factor with suicide attempts in depressed patients. Neuropsychobiology 2008;57:139-145.

23. Schenkel LC, Segal J, Becker JA, Manfro GG, Bianchin MM, LeistnerSegal S. The BDNF Val66Met polymorphism is an independent risk factor for high lethality in suicide attempts of depressed patients. Prog Neuropsychopharmacol Biol Psychiatry 2010;34:940-944.

24. Schosser A, Carlberg L, Calati R, Serretti A, Massat I, Spindelegger C, et al. The impact of BDNF polymorphisms on suicidality in treatmentresistant major depressive disorder: a European multicenter study. Int J Neuropsychopharmacol 2017;20:782-787.

25. Spalletta G, Morris DW, Angelucci F, Rubino IA, Spoletini I, Bria P, et al. BDNF Val66Met polymorphism is associated with aggressive behavior in schizophrenia. Eur Psychiatry 2010;25:311-313.

26. Vincze I, Perroud N, Buresi C, Baud P, Bellivier F, Etain B, et al. Association between brain-derived neurotrophic factor gene and a severe form of bipolar disorder, but no interaction with the serotonin transporter gene. Bipolar Disord 2008;10:580-587.

27. Wang JY, Wang XT, Wang LL, Jia CX. Association of brain-derived neurotrophic factor G196A and attempted suicide: a case-control study in rural China. Neuropsychobiology 2015;72:91-96.

28. Xia H, Zhang G, Du X, Zhang Y, Yin G, Dai J, et al. Suicide attempt, clinical correlates, and BDNF Val66Met polymorphism in chronic pa- 
tients with schizophrenia. Neuropsychology 2018;32:199-205.

29. Zai CC, Manchia M, Sonderby IE, Yilmaz Z, De Luca V, Tiwari AK, et al. Investigation of the genetic interaction between $\mathrm{BDNF}$ and $\mathrm{DRD} 3$ genes in suicidical behaviour in psychiatric disorders. World J Biol Psychiatry 2015;16:171-179.

30. Kim JM, Kang HJ, Bae KY, Kim SW, Shin IS, Kim HR, et al. Association of BDNF promoter methylation and genotype with suicidal ideation in elderly Koreans. Am J Geriatr Psychiatry 2014;22:989-996.

31. American Psychiatric Association. Diagnostic and Statistical Manual of Mental Disorders, 4th Edition, Text Revision (DSM-IV-TR). Washington DC: American Psychiatric Association; 2000.

32. Sears C, Markie D, Olds R, Fitches A. Evidence of associations between bipolar disorder and the brain-derived neurotrophic factor (BDNF) gene. Bipolar Disord 2011;13:630-637.

33. Weisman $\mathrm{AD}$, Worden JW. Risk-rescue rating in suicide assessment. Arch Gen Psychiatry 1972;26:553-560.

34. Yi JS, Bae SO, Ahn YM, Park DB, Noh KS, Shin HK, et al. Validity and reliability of the Korean version of the Hamilton Depression Rating Scale (K-HDRS). J Korean Neuropsychiatr Assoc 2005;44:456-465.

35. Lee SR, Lee WH, Park JS, Kim SM, Kim JW, Shim JH. The study on reli- ability and validity of Korean version of the Barratt Impulsiveness Scale11-Revised in nonclinical adult subjects. J Korean Neuropsychiatr Assoc 2012;51:378-386.

36. Gonzalez-Castro TB, Hernandez-Diaz Y, Juarez-Rojop IE, Lopez-Narvaez ML, Tovilla-Zarate CA, Genis-Mendoza A, et al. The role of C957T, TaqI and Ser311Cys polymorphisms of the DRD2 gene in schizophrenia: systematic review and meta-analysis. Behav Brain Funct 2016;12:29.

37. The Allele FREquency Database (ALFRED). Resource of gene frequency data on human populations supported by the U. S. National Science Foundation. Available at: https://alfred.med.yale.edu/alfred/SiteTable1A_ working.asp?siteuid=SI018450S. Accessed June 27, 2019.

38. Choi KH, Wang SM, Yeon B, Suh SY, Oh Y, Lee HK, et al. Risk and protective factors predicting multiple suicide attempts. Psychiatry Res 2013; 210:957-961.

39. Hur JW, Lee BH, Lee SW, Shim SH, Han SW, Kim YK. Gender differences in suicidal behavior in Korea. Psychiatry Investig 2008;5:28-35.

40. Wang SM, Hwang S, Yeon B, Choi KH, Oh Y, Lee HK, et al. Suicide risk assessments: which suicide risk factors psychiatric residents consider significant? Psychiatry Investig 2015;12:324-329. 